\title{
Conjugated Linoleic Acid n-6
}

National Cancer Institute

\section{Source}

National Cancer Institute. Conjugated Linoleic Acid n-6. NCI Thesaurus. Code C68336.

A polyunsaturated long-chain fatty acid with an 18-carbon backbone and exactly two double bonds, originating from the 10th and 12th positions from the methyl end, resulting in a conjug ated section of the acyl chain. Three stereoisomers of conjug ated linoleic acid, n-6 are recognized. 